\title{
SEPARATION OF AROMATIC AND ALIPHATIC HYDROCARBONS WITH IONIC LIQUIDS
}

G. Wytze Meindersma, Anita (J.G.) Podt, Marianne B. Klaren and André B. de Haan

University of Twente, Separation Technology Group/Faculty of Science and Technology P.O. Box 217, 7500 AE ENSCHEDE, The Netherlands

e-mail: g.w.meindersma@utwente.nI

Key words: ionic liquids, extraction, toluene, heptane, aromatic hydrocarbons, naphtha cracker

Copyright (@): G.W. Meindersma, University of Twente, Enschede, The Netherlands

Prepared for presentation at the AIChE 2004 Annual Meeting, Austin, TX, Nov. 7-12

Unpublished

AIChE shall not be responsible for statements or opinions contained in papers or printed in its publications. 


\section{ABSTRACT}

Naphtha cracker feeds may contain 10-25 wt\% aromatic compounds. Removal of these aromatic compounds from the feed to the cracker would offer several advantages: higher capacity, higher thermal efficiency and less coke formation. In this work, we investigated the separation of toluene from heptane by extraction with ionic liquids.

Several ionic liquids are suitable for extraction of toluene from toluene/heptane mixtures. The selectivities for the aromatic/aliphatic hydrocarbon separation with all ionic liquids tested increase with decreasing aromatic content in the feed. The toluene/heptane selectivities at $10 \%$ toluene in the feed at $\mathrm{T}=40^{\circ} \mathrm{C}$ and $75^{\circ} \mathrm{C}$ with several ionic liquids ([emim] $\mathrm{HSO}_{4}$, [mmim] methylsulfate, [emim] ethylsulfate, [bmim]BF 4 , [emim] tosylate, [mebupy]BF 4 and [mebupy] methylsulfate) are a factor of 1.5-2.5 higher compared to those obtained with sulfolane, which is a conventional solvent for the extraction of aromatic hydrocarbons from a mixed aromatic/aliphatic hydrocarbon stream. The three most suitable ionic liquids from the ionic liquids tested for the separation of aromatic and aliphatic hydrocarbons are: [mebupy] $\mathrm{BF}_{4}$, [mebupy] $\mathrm{CH}_{3} \mathrm{SO}_{4}$ and $[\mathrm{bmim}] \mathrm{BF}_{4}$ and at $75^{\circ} \mathrm{C}$ also [emim] tosylate. The ionic liquid [mebupy]BF 4 is selected for further testing in our extraction pilot plant.

Because ionic liquids have a negligible vapour pressure, evaporating the extracted hydrocarbons from the ionic liquid phase could achieve the recovery of the ionic liquid. A conceptual process scheme for the extraction has been set up. Preliminary calculations show that both the investment costs and the energy costs will be considerably lower with ionic liquids compared to using sulfolane as the solvent. 


\section{INTRODUCTION}

\section{NAPHTHA CRACKER PROCESS}

Naphtha crackers convert naphtha into ethylene, propylene and other hydrocarbons by thermal cracking. Some cracker feeds contain a considerable amount of aromatic compounds, in the range of $10-25 \mathrm{wt} \%$, that are not converted into olefins in the cracker furnaces, but remain as such in the process stream. The separation of aromatic hydrocarbons (benzene, toluene, ethyl benzene and xylenes) from $C_{4}-C_{10}$ aliphatic hydrocarbon mixtures is challenging since these hydrocarbons have boiling points in a close range and several combinations form azeotropes. The conventional processes for the separation of these aromatic and aliphatic hydrocarbon mixtures are liquid extraction, suitable for the range of 20-65 wt\% aromatic content, extractive distillation for the range of 65-90 wt $\%$ aromatics and azeotropic distillation for high aromatic content, >90 wt $\%$ (Weissermel and Arpe, 2003).

In ethylene cracker plants, industrial separation of aromatic compounds and $\mathrm{C}_{5}{ }^{+}$ aliphatic hydrocarbons from the cracker products is carried out by extractive or azeotropic distillation of the $\mathrm{C}_{5}{ }^{+}$hydrocarbon stream. Typical solvents used are polar components such as sulfolane, N-methyl pyrrolidone (NMP), N-formyl morpholine (NFM) or ethylene glycols. This implicates additional distillation steps to separate the extraction solvent from both the extract and raffinate phases, and to purify the solvent, with consequently, additional investments and energy consumption.

\section{OBJectives}

Although separation of aromatic and aliphatic hydrocarbons after the furnace section is industrial practice, selective removal of aromatic compounds from the cracker feed has not yet been considered. However, removing the major part of the aromatic compounds present in the feed to the crackers would offer several important advantages. They occupy a large part of the capacity of the furnaces, put an extra load on the separation section of the $\mathrm{C}_{5}{ }^{+}$-aliphatic compounds and the presence of aromatic compounds in the feed to the cracker has a negative influence on the thermal efficiency. Furthermore, the presence of aromatic compounds in the feed is undesirable, because they tend to foul the radiation sections (coking of the coils) and the Transfer Line Exchangers. The improved margin will be around $\$ 20 /$ ton of feed or $\$ 48$ million per year for a naphtha cracker with a feed capacity of 300 ton $/ \mathrm{hr}$. Preliminary calculations showed that extraction with conventional solvents is not an option since additional separation steps are required to purify the raffinate, extract and solvent streams, which would induce high investment and energy costs. Extraction of aromatics with ionic liquids is expected to require less process steps and less energy consumption than extraction with conventional solvents because ionic liquids have a negligible vapour pressure.

The extraction of toluene from mixtures of toluene and heptane is used as a model for the aromatic/aliphatic separation. The solvent sulfolane is used as a benchmark for this separation. 


\section{EXTRACTION WITH IONIC LIQUIDS}

Ionic liquids are organic salts that are liquid at low temperatures $\left(<100^{\circ} \mathrm{C}\right)$ and consist of cations based on methylimidazolium [Rmim], N-butylpyridinium [R-N-bupy], quaternary ammonium or phosphonium ions (Figure 1) and others, and anions such as hexafluorophosphate, tetrafluoroborate, alkylsulfates, alkylsulfonates, chloride, bromide, nitrate, sulfate, aluminium chloride, triflate $\left(\mathrm{CF}_{3} \mathrm{SO}_{3}{ }^{-}\right)$, bis(trifyl)imide $\left(\left(\mathrm{CF}_{3} \mathrm{SO}_{2}\right)_{2} \mathrm{~N}^{-}\right)$, etc.

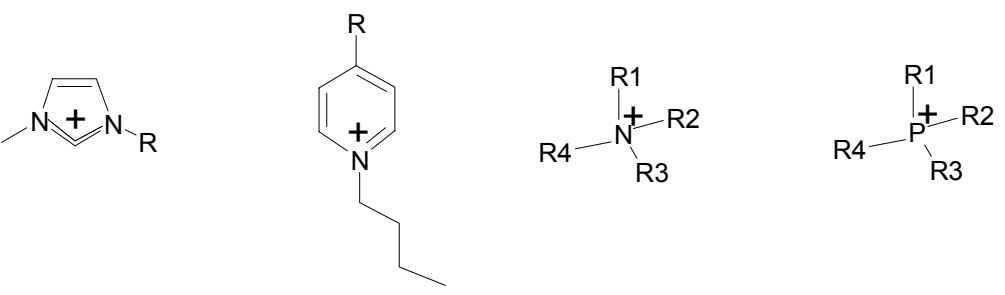

Figure 1. Structure of 1-R-3-methylimidazolium, 4-R-N-butylpyridinium, quaternary ammonium and quaternary phosphonium cations.

The $\mathrm{R}$ group of the cation is variable (e.g. methyl, ethyl, butyl, etc.). The variability of the anion and $\mathrm{R}$ groups in the imidazolium, pyridinium, ammonium or phosphonium cations may be used to adjust the properties of the ionic liquids. Ionic liquids possess a number of properties, which may be of importance in their application as extractive media in liquid/liquid extraction processes.

The requirements of a suitable extraction solvent for the separation of aromatic and aliphatic hydrocarbons are:

- High solubility of aromatic hydrocarbons in the IL

- No or low solubility of aliphatic hydrocarbons in the IL

- High separation factor and a high distribution coefficient

- Simple recovery of the IL from both the extract and the raffinate phase

\section{SELECTION OF SUITABLE IONIC LIQUIDS}

Aromatic hydrocarbons have low activity coefficients at infinite solution in several ionic liquids with methylimidazolium based cations with alkyl groups methyl, methyl-ethyl, ethyl, butyl, hexyl or octyl and anions such as $\mathrm{BF}_{4}^{-}, \mathrm{PF}_{6}^{-}, \mathrm{Cl}^{-}, \mathrm{I}_{3}{ }^{-}, \mathrm{AlCl}_{4}^{-},\left(\mathrm{CF}_{3} \mathrm{SO}_{2}\right)_{2} \mathrm{~N}^{-}(=$ $\mathrm{Tf}_{2} \mathrm{~N}^{-}$) or $\mathrm{C}_{2} \mathrm{H}_{5} \mathrm{OSO}_{3}{ }^{-}$(Blanchard and Brennecke, 2001; David et al., 2003; Domańska and Marciniak, 2003; Dupont et al., 2000; Gmehling and Krummen, 2003; Heintz et al., 2002; Holbrey et al., 2003; Huddleston et al., 1998; Krummen et al., 2002; Letcher et al., 2003; Letcher and Deenadayalu, 2003; Selvan et al., 2000), and in [4-methyl-Nbutylpyridinium]BF 4 (Heintz et al., 2001), while aliphatic hydrocarbons (alkanes and cycloalkanes) show high activity coefficients. This suggests that these ionic liquids can be used as extractants for the separation of aromatic hydrocarbons from aliphatic hydrocarbons.

There are only a few publications concerning extractive separations of aromatic/aliphatic hydrocarbon mixtures using ionic liquids, namely with the ionic liquids $[\mathrm{emim}] \mathrm{l}_{3}$, [bmim $]_{3}$ (Selvan et al. 2000) and [omim]Cl (Letcher and Deenadayalu, 2003). 
The ionic liquids [emim] $l_{3}$ and $[\mathrm{bmim}] \mathrm{l}_{3}$ proved to be very corrosive in our earlier research (Meindersma et al. 2004) and we decided not to follow up on these ionic liquids as extractants. The selectivity reported for the separation of benzene/heptane with [omim] Cl is too low: $S=6.1$ at a benzene content of $27 \%$.

Krummen et al. (2002) have measured activity coefficients at infinite dilution $\left(\gamma_{i}^{\infty}\right)$ for several solutes in the ionic liquids $[\mathrm{mmim}] \mathrm{Tf}_{2} \mathrm{~N}$, [emim] $\mathrm{Tf}_{2} \mathrm{~N},[\mathrm{bmim}] \mathrm{Tf}_{2} \mathrm{~N}$ and $[\mathrm{emim}]$ ethylsulfate. From these data, distribution coefficients $\left(k_{i}^{\infty}=1 / \gamma_{i}^{\infty}\right)$ and selectivities $\left(S_{i j}^{\infty}=\right.$ $\gamma_{i}^{\infty}\left(\gamma_{j}^{\infty}\right)$ of these solutes can be calculated. The ionic liquid [emim] ethylsulfate showed the highest selectivity ( $\mathrm{S}=36.4$ at $313.15 \mathrm{~K}$ ) for toluene/n-heptane, which is higher than the selectivity with sulfolane $(S=31)$. The ionic liquid $[\mathrm{bmim}] \mathrm{Tf}_{2} \mathrm{~N}$ showed a lower selectivity and a higher capacity (distribution coefficient) than the ILs with cations [emim] $]^{+}$and $[\mathrm{mmim}]^{+}$. The same trend is seen for the other aromatic/aliphatic hydrocarbons tested: benzene/cyclohexane and benzene/hexane. From these data, it is clear that a shorter Rgroup is favourable for the aromatic/aliphatic selectivity, but results in a decrease in capacity.

Since the $\left[\mathrm{Tf}_{2} \mathrm{~N}\right]^{-}$- containing ILs showed lower toluene/heptane selectivities than sulfolane, we decided not to test these ionic liquids. Brennecke and Maginn (2001) reported that halide containing ILs are certainly corrosive and Swatloski et al. (2003) reported that $\mathrm{HF}$ formation is possible when using $\left[\mathrm{bmmim}_{\mathrm{PF}}\right.$. Therefore, ionic liquids with $\mathrm{PF}_{6}{ }^{-}$as anion were excluded.
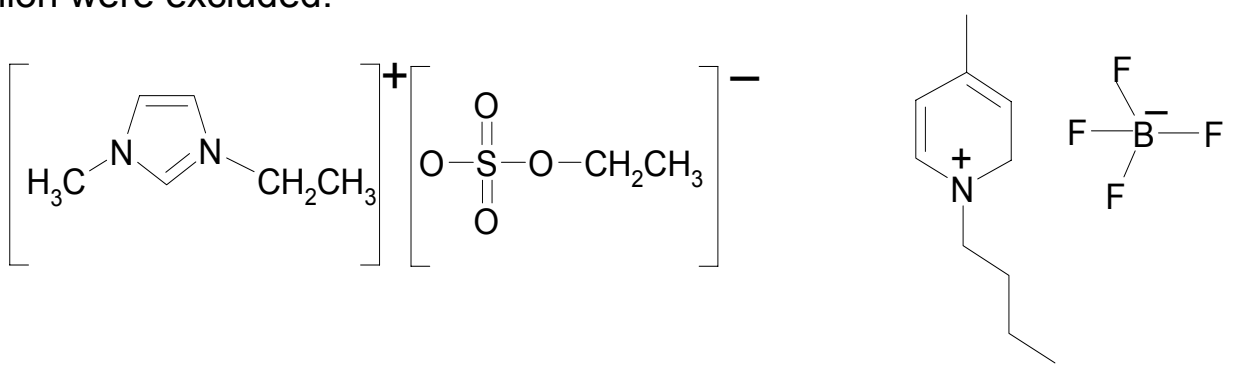

Figure 2. 1-ethyl-3-methylimidazolium ethylsulfate and 3-methyl-N-butylpyridinium tetrafluoroborate.

The ionic liquids [emim] ethylsulfate and [mebupy]BF 4 (Figure 2) were tested for the separation of toluene and heptane with several toluene concentrations in heptane. Other ionic liquids were used for the separation of 5,10 and $15 \%$ toluene in heptane: $[\mathrm{Hmim}] \mathrm{HSO}_{4},[\mathrm{mmim}]$ methylsulfate, $[\mathrm{mmim}]$ dimethylphosphate, [emim] $\mathrm{HSO}_{4}$, [emim] methylsulfonate, [emim] diethylphosphate, [emim] $\mathrm{BF}_{4},\left[\mathrm{bmim}_{\mathrm{B}} \mathrm{BF}_{4}, \quad[\mathrm{omim}] \mathrm{BF}_{4}\right.$, [bupy] methylsulfate, [mebupy] methylsulfate, [emim] tosylate, ethyl-isoquinolinium ethylsulfate, tetrabutylphosphonium bis[oxalato(2-)]borate and methyl-tributylammonium methylsulfate,

If the same trend is occurring as with the $\left[\mathrm{Tf}_{2} \mathrm{~N}\right]^{-}$-containing ILs, we expect a higher selectivity and a lower capacity using [mmim] methylsulfate or [mmim] dimethylphosphate than with [emim] ethylsulfate or [emim] diethylphosphate, because both the R-group of the cation and the alkyl chain in the anion is shorter. Also with the ILs [emim]BF ${ }_{4}$, [bmim] $\mathrm{BF}_{4}$ and [omim] $\mathrm{BF}_{4}$ a decreasing selectivity and an increasing distribution coefficient is expected in this order. 


\section{EXPERIMENTAL SECTION}

The ionic liquid 1-ethyl-3-methylimidazolium ethylsulfate was prepared from 1methylimidazole (Merck-Schuchardt, >99\%) and diethylsulfate (Fluka, >99\%) according to the procedure described by Holbrey et al. (2002). The ionic liquid 1-ethyl-isoquinolinium ethylsulfate was prepared form isoquinoline (Fluka, >97\%) and diethylsulfate according to the procedure described by Willems and Nys (1957). The ionic liquids 1,3dimethylimidazolium methylsulfate (98\%), 1,3-dimethylimidazolium dimethylphoshate $(>98 \%)$ and 1-ethyl-3-methylimidazolium tosylate $(98 \%)$ were purchased from Solvent Innovation. Sulfolane $(>98 \%)$ and the ionic liquids 1-ethyl-3-methylimidazolium tetrafluoroborate $(>97 \%)$, 1-octyl-3-methylimidazolium tetrafluoroborate $(>97 \%)$ and $4-$ methyl-N-butylpyridinium tetrafluoroborate $(>97 \%)$ were purchased from Fluka. Toluene (p.a.), n-heptane (p.a.) and the ionic liquids 1-butyl-3-methylimidazolium tetrafluoroborate, $\mathrm{N}$-butylpyridinium methylsulfate, 3-methyl-N-butylpyridinium methylsulfate and tetrabutylphosphonium bis[oxalato(2-)]borate (purity: for synthesis) were purchased from Merck. The ionic liquids 1-methylimidazolium hydrogensulfate, 1-ethyl-3methylimidazolium hydrogensulfate, 1-ethyl-3-methyl-imidazolium methylsulfonate, 1-ethyl3-methylimidazolium diethylphosphate and methyl-tributylammonium methylsulfate were obtained from BASF.

Before each experiment, the ionic liquids were dried at $75^{\circ} \mathrm{C}$ under reduced pressure in a rotary evaporator. Liquid-liquid extraction experiments were carried out in jacketed vessels with a volume of approximately $70 \mathrm{~mL}$. The top of a vessel was closed using a PVC cover, through which the stirrer shaft passed. Two stainless steel propellers were used with an electronic stirrer. The vessels were jacketed to circulate water from a water bath, maintaining the temperature inside the vessels at either 40 or $75^{\circ} \mathrm{C}$.

The concentrations of toluene and $\mathrm{n}$-heptane in the samples were analysed by gas chromatography. Because the ionic liquid has no vapour pressure, it could not be analysed by GC. Therefore, the concentrations of the ionic liquid in both phases were calculated by using a mass balance.

\section{RESULTS AND DISCUSSION}

\section{EXPERIMENTS WITH [EMIM] ETHYLSULFATE AND [MEBUPY]BF 4}

Liquid-liquid equilibrium data were collected for mixtures of toluene and heptane at 40 and $75^{\circ} \mathrm{C}$ using the ionic liquids [emim] ethylsulfate and [mebupy] $\mathrm{BF}_{4}$. The distribution coefficient, $D_{i}$, is directly calculated from the ratio of the mole fractions in the extract and raffinate phases. The distribution coefficients of toluene and heptane are defined by the ratio of the mole fractions of the solute in the extract (IL) phase and in the raffinate (organic) phase, according to:

$$
D_{\text {tol }}=C^{\mathrm{IL}}{ }_{\text {tol }} / C^{\text {org }} \text { tol and } D_{\text {hept }}=C^{\mathrm{LL}}{ }_{\text {hept }} / \mathrm{C}^{\text {org }}{ }_{\text {hept }}
$$


The selectivity, $S_{\text {tol/hept, }}$ of toluene/heptane is defined as the ratio of the distribution coefficients of toluene and heptane:

$\mathrm{S}_{\text {tol/hept }}=\mathrm{D}_{\text {tol }} / \mathrm{D}_{\text {hept }}=\left(\mathrm{C}^{\mathrm{lL}}{ }_{\text {tol }} / \mathrm{C}^{\text {org }}{ }_{\text {tol }}\right) /\left(\mathrm{C}^{\mathrm{lL}}{ }_{\text {hept }} / \mathrm{C}^{\text {org }}{ }_{\text {hept }}\right)$
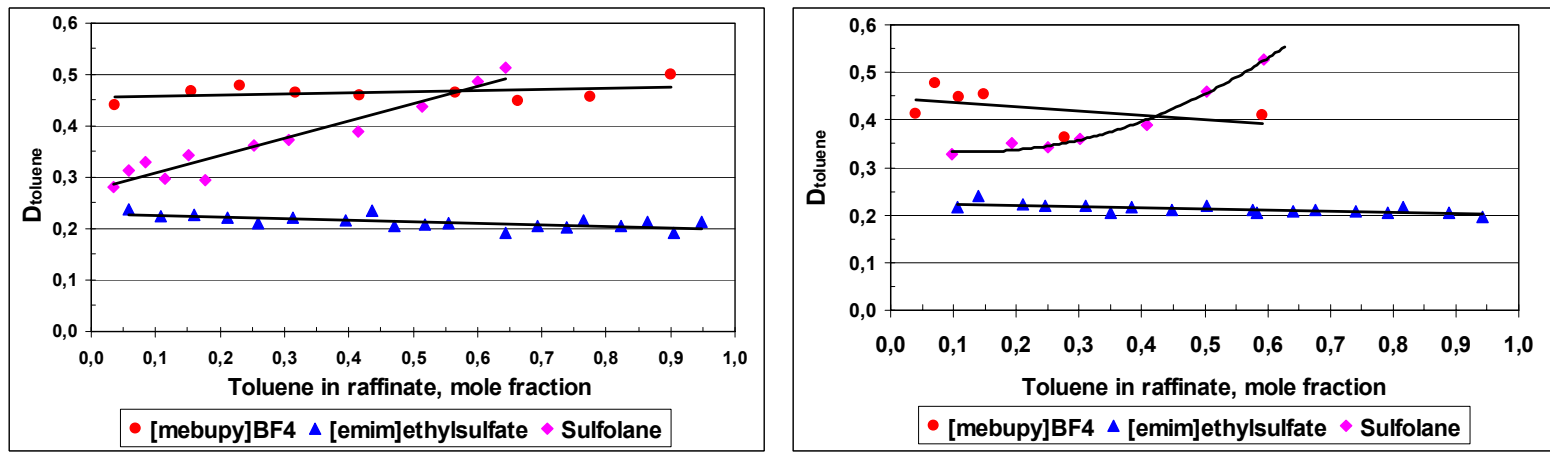

Figure 3. Distribution coefficients for toluene, $T=40^{\circ} \mathrm{C}$ (left) and $75^{\circ} \mathrm{C}$ (right)

From Figure 3, it can be seen that the distribution coefficient of toluene, using [emim] ethylsulfate as extractant, remains slightly above 0.2 over the entire concentration range for both 40 and $75^{\circ} \mathrm{C}$. The distribution coefficient of toluene with [mebupy]BF $\mathrm{B}_{4}$ is about 0.46 over the entire concentration range at $40^{\circ} \mathrm{C}$ and about 0.43 at $75^{\circ} \mathrm{C}$. The distribution coefficient of toluene with sulfolane decreased from 0.51 at $65 \%$ toluene to 0.28 at $5 \%$ toluene at $40^{\circ} \mathrm{C}$ and from 0.56 at $65 \%$ toluene to 0.33 at $10 \%$ toluene at $75^{\circ} \mathrm{C}$.
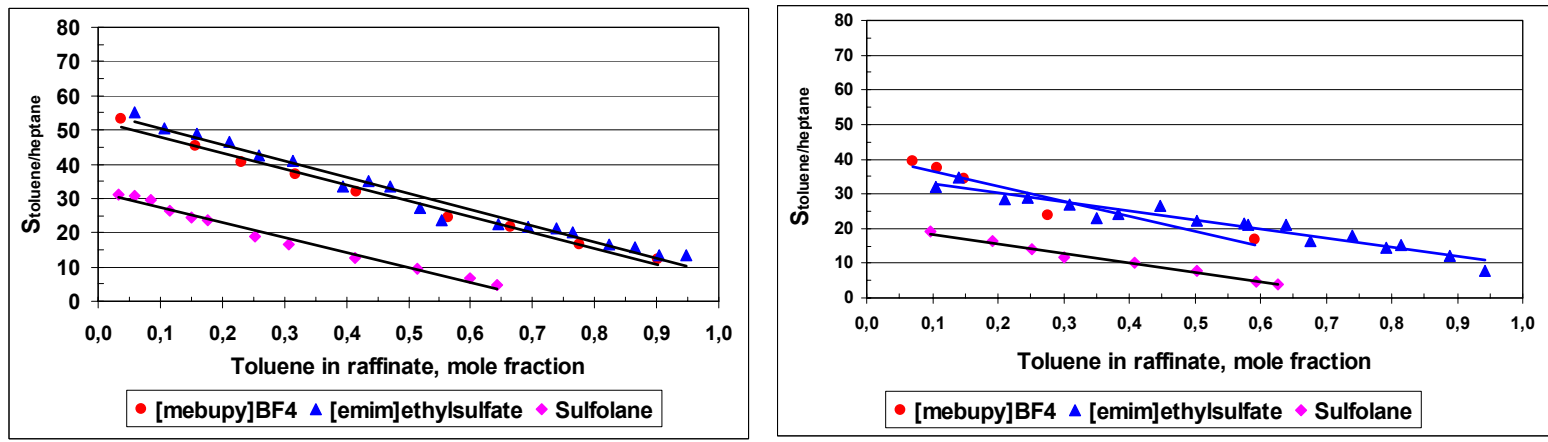

Figure 4. Toluene/heptane selectivities, $T=40^{\circ} \mathrm{C}$ (left) and $75^{\circ} \mathrm{C}$ (right)

With [emim] ethylsulfate the toluene/heptane selectivity at $40^{\circ} \mathrm{C}$ increases from 13.4 to 55.3 with decreasing toluene content in the feed, from 95 to $5 \mathrm{v} / \mathrm{v} \%$ (Figure 4, left). The toluene/heptane selectivity at $75^{\circ} \mathrm{C}$ increases from $8(95 \%$ toluene in the feed) to 35 (5\% toluene in the feed) (Figure 4, right). The selectivity at $75^{\circ} \mathrm{C}$ is lower than at $40^{\circ} \mathrm{C}$, mainly due to higher concentrations of heptane in the extract (IL phase), resulting in higher distribution coefficients of heptane $\left(0.0043\right.$ at $40^{\circ} \mathrm{C}$ and 0.0057 at $75^{\circ} \mathrm{C}$ with $5 \%$ toluene), while the distribution coefficient of toluene remains about constant: 0.21 at $40^{\circ} \mathrm{C}$ and 0.22 at $75^{\circ} \mathrm{C}$. The higher distribution coefficient of heptane at a higher temperature is in accordance with the findings of Krummen et al. (2002). From his data, distribution coefficients of heptane with [emim] ethylsulfate can be calculated: 0.0051 at $40^{\circ} \mathrm{C}$ and 0.0069 at $60^{\circ} \mathrm{C}$. With [mebupy]BF 4 the toluene/heptane selectivity increases from 12 to 53 
(95 to $5 \%$ toluene in the feed) at $40^{\circ} \mathrm{C}$ and from 17 to 39 (65 to $10 \%$ toluene in the feed) at $75^{\circ} \mathrm{C}$.

Both the distribution coefficients of toluene and the toluene/heptane selectivities with [emim] ethylsulfate and with [mebupy]BF $\mathrm{BF}_{4}$ in our extraction experiments are higher than the values calculated by respectively Krummen (2002) and Heintz (2002) from activity coefficients at infinite dilution. The distribution coefficients of toluene with [emim] ethylsulfate at $40^{\circ} \mathrm{C}$ are: 0.214 (exp.) and 0.187 (act. coeff.) and with [mebupy]BF 0.46 and 0.33 , respectively. We measured a toluene/heptane selectivity at $40^{\circ} \mathrm{C}$ of 55.3 at $5 \mathrm{v} / \mathrm{v} \%$ toluene in the feed with [emim] ethylsulfate, compared to 36.4 from the data of Krummen et al. With [mebupy]BF 4 the experimental and calculated toluene/heptane selectivities at $40^{\circ} \mathrm{C}$ are 53.1 and 32.8 . The differences in these values are probably due to the different methods used to obtain the data, because Krummen and Heintz used VLE measurements to obtain activity coefficients at infinite dilution and calculated the capacity and selectivity from the activity coefficients. We have used LLE experiments and calculated the distribution coefficients and selectivities directly from the concentrations of the components in the extract and raffinate phases with formulas (1) and (2).

The distribution coefficients obtained with [emim] ethylsulfate are lower than with sulfolane, but with [mebupy]BF ${ }_{4}$, at least in the concentration range lower than $60 \%$ toluene at $40^{\circ} \mathrm{C}$ and lower than $40 \%$ at $75^{\circ} \mathrm{C}$, are higher than with sulfolane (Figure 3). The toluene/heptane selectivities with these two ILs are a factor of 2-3 higher than those with sulfolane. The toluene/heptane selectivity with sulfolane as extractant increases from 4.6 $\left(65 \%\right.$ toluene in the feed) to $31\left(5 \%\right.$ toluene in the feed) at $40^{\circ} \mathrm{C}$ and from $3.7(65 \%$ toluene) to $19\left(10 \%\right.$ toluene) at $75^{\circ} \mathrm{C}$, as can be seen in Figure 4 . A higher selectivity means less extraction stages and a higher distribution coefficient requires a lower solvent to feed ratio.

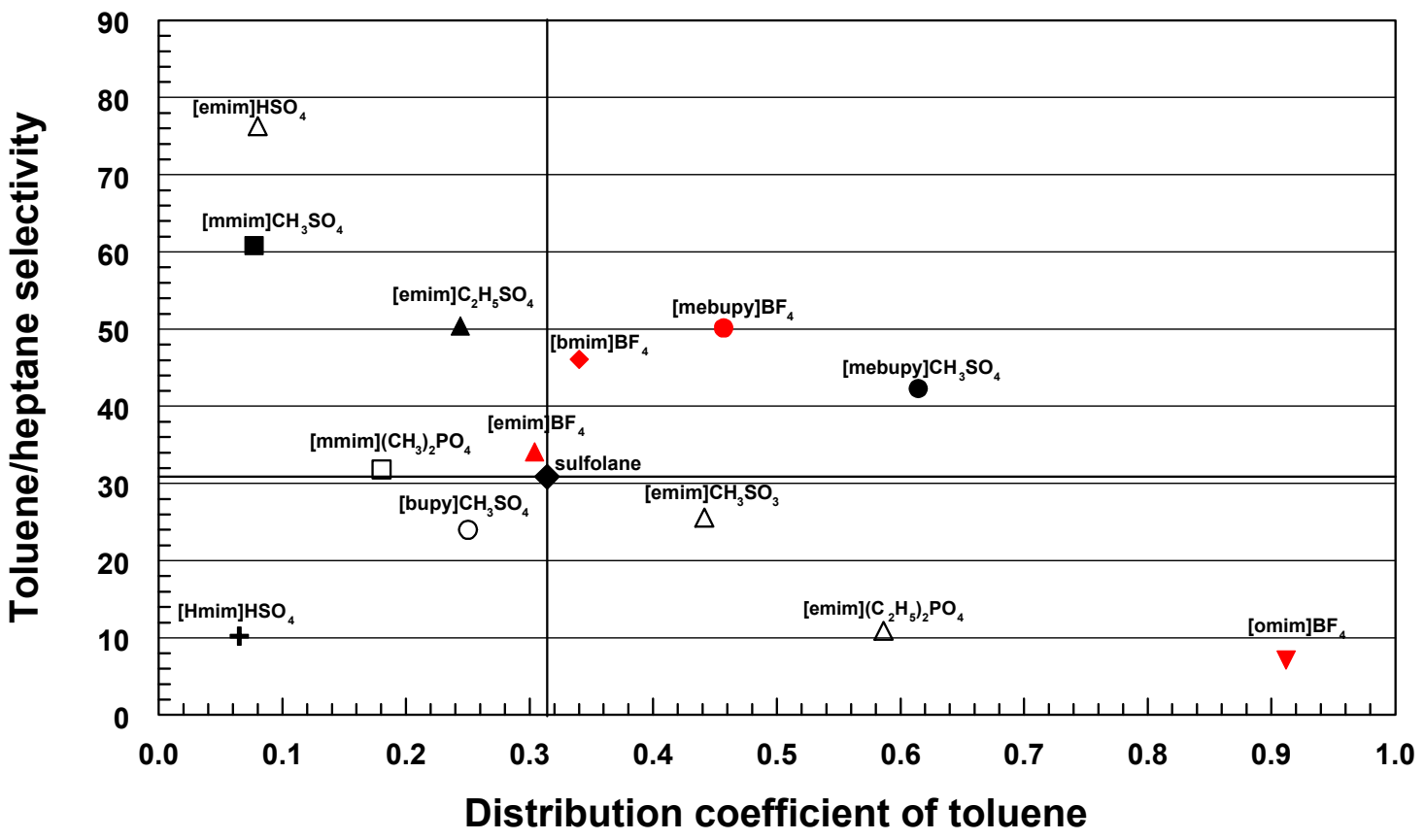

Figure 5. Toluene/heptane separation with ionic liquids, $10 \%$ toluene, $T=40^{\circ} \mathrm{C}$ 
Tests with 5, 10 and $15 \%$ toluene in heptane were carried out with the other ionic liquids. The results of the experiments with $10 \%$ toluene in the feed at $40^{\circ} \mathrm{C}$ are shown in Figure 5 and the results at $75^{\circ} \mathrm{C}$ in Figure 6 . In these figures, the toluene/heptane selectivity is shown as function of the distribution coefficient of toluene.

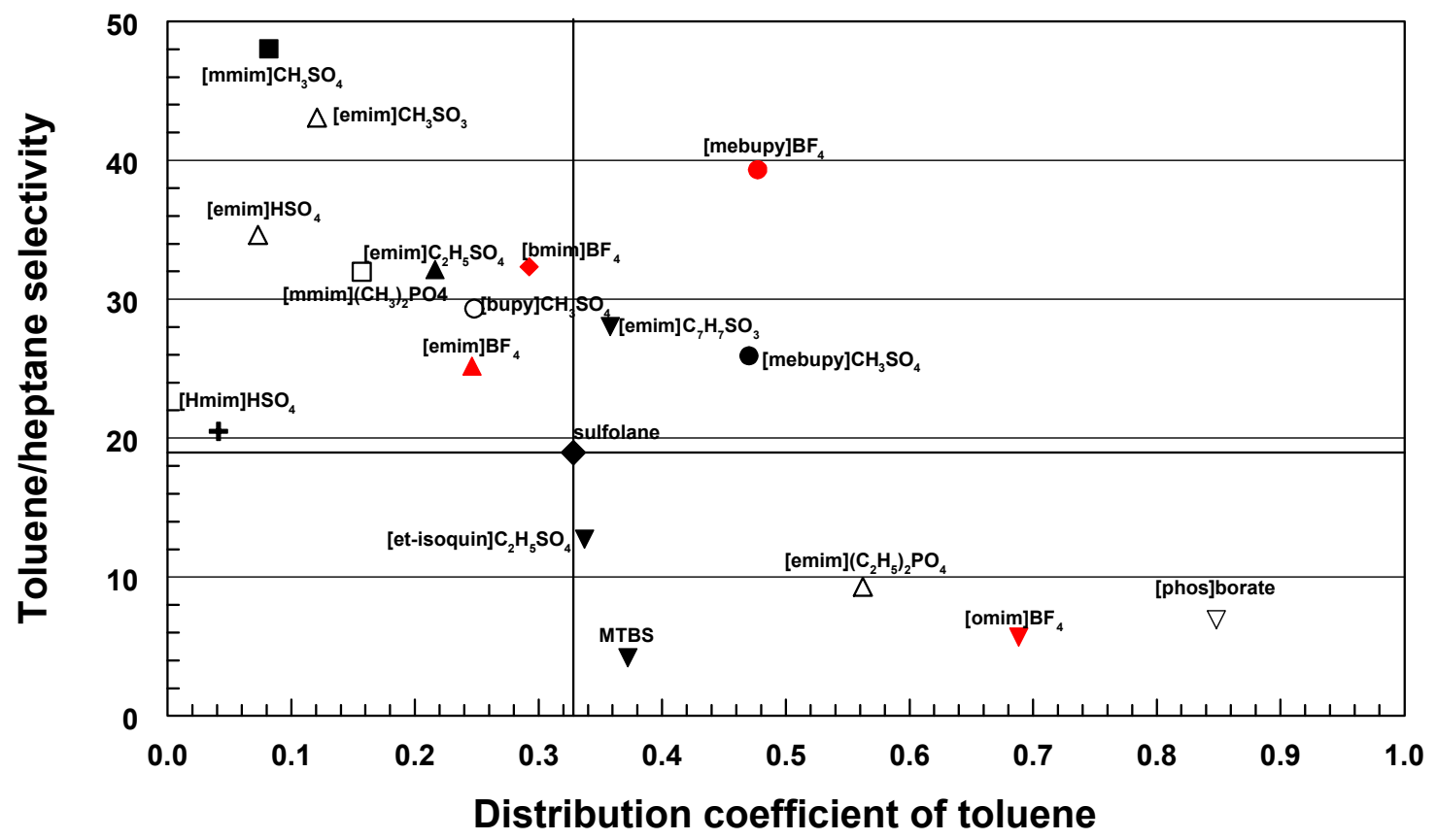

Figure 6. Toluene/heptane separation with ionic liquids, $10 \%$ toluene, $T=75^{\circ} \mathrm{C}$

Some of ionic liquids used are not liquid at $40^{\circ} \mathrm{C}$, but have higher melting points. Four ionic liquid were tested at $75^{\circ} \mathrm{C}$ only: [emim] tosylate ([emim] $\mathrm{C}_{7} \mathrm{H}_{7} \mathrm{SO}_{3}$ ), [1-ethylisoquinolinium] ethylsulfate $\left(\left[\mathrm{C}_{9} \mathrm{H}_{7} \mathrm{~N}-\mathrm{C}_{2} \mathrm{H}_{5}\right] \mathrm{C}_{2} \mathrm{H}_{5} \mathrm{SO}_{4}\right), \quad$ [tetrabutylphosphonium] bis[oxalato(2-)]borate] $\left(\left[\left(\mathrm{C}_{4} \mathrm{H}_{9}\right)_{4} \mathrm{P}\right] \mathrm{C}_{4} \mathrm{BO}_{8}\right)$ and [methyl-tributylammonium] methylsulfate $\left(\left[\mathrm{CH}_{3}-\mathrm{N}-\left(\mathrm{C}_{4} \mathrm{H}_{9}\right)_{3}\right] \mathrm{CH}_{3} \mathrm{SO}_{4}\right.$ or MTBS $)$.

At $75^{\circ} \mathrm{C}$, the distribution coefficients of toluene with the most ionic liquids tested are lower compared to those at $40^{\circ} \mathrm{C}$. As the distribution coefficients of heptane increase with temperature in most cases, the toluene/heptane selectivities will decrease with temperature. The distribution coefficient of toluene with sulfolane at $75^{\circ} \mathrm{C}$ is about 0.33 and the toluene/heptane selectivity is 19 , compared to 0.31 and 31 at $40^{\circ} \mathrm{C}$.

\section{EfFECT Of ALKYL CHAIN LENGTH}

Comparison of the experiments with ionic liquids [emim] ethylsulfate and [mmim] methylsulfate and with [emim] diethylphosphate and [mmim] dimethylphosphate (Figures 5 and 6) lead to the conclusion that a shorter alkyl chain on the imidazolium ion is favourable for higher aromatic/aliphatic selectivities, but results to lower distribution coefficients, as expected from the data of Krummen (2002). The same observation holds for [emim]BF 4 and [omim]BF . However, if the results of [emim]BF $_{4}$ and [bmim]BF 4 are compared, the 
conclusion is that a butyl chain on the imidazolium ion with $\mathrm{BF}_{4}{ }^{-}$as anion gives both a higher distribution coefficient of toluene and a higher toluene/heptane selectivity.

Apparently, the absence of a alkyl chain on the imidazolium group leads to a lower selectivity as can be seen by comparing the results of $[\mathrm{Hmim}] \mathrm{HSO}_{4}$ and [emim] $\mathrm{HSO}_{4}$ $\left(40^{\circ} \mathrm{C}: \mathrm{S}_{\mathrm{T} / \mathrm{H}}=10.2\right.$ and $\mathrm{S}_{\mathrm{T} / \mathrm{H}}=76.3 ; 75^{\circ} \mathrm{C}: \mathrm{S}_{\mathrm{T} / \mathrm{H}}=20.5$ and $\mathrm{S}_{\mathrm{T} / \mathrm{H}}=43.6$ respectively $)$. The same observation can be made for the butylpyridinium ion at $40^{\circ} \mathrm{C}$, as the methyl group has a favourable effect on both the distribution coefficient of toluene and the toluene/heptane selectivity, as can be seen by comparing [bupy] methylsulfate $\left(D_{T}=0.25\right.$, $\left.S_{T / H}=24.0\right)$ and [mebupy] methylsulfate $\left(D_{T}=0.61, S_{T / H}=42.3\right)$. However, at $75^{\circ} \mathrm{C}$, the toluene distribution coefficient with [mebupy] $\mathrm{CH}_{3} \mathrm{SO}_{4}$ is higher than that with [bupy] $\mathrm{CH}_{3} \mathrm{SO}_{4}(0.47$ and 0.25$)$, but the toluene/heptane selectivity is slightly lower (26 and 29).

\section{EFFECT OF THE CATION AND ANION}

Ionic liquids containing the methyl-N-butylpyridinium cation have a more aromatic character than the imidazolium based ionic liquids and this results not only in a high toluene/heptane selectivity, but also in a high distribution coefficient of toluene. The toluene distribution coefficients of the ionic liquids [mebupy] $\mathrm{BF}_{4}$ and $\left[\right.$ mebupy] $\mathrm{CH}_{3} \mathrm{SO}_{4}$ at $40^{\circ} \mathrm{C}$ are 0.45 and 0.61 , and the toluene/heptane selectivities 50 and 42 respectively. Also at $75^{\circ} \mathrm{C}$, both the toluene distribution coefficients $(0.48$ and 0.47$)$ and the selectivities (39 and 26) with these two ionic liquids are higher than those with sulfolane. The quaternary phosphonium and ammonium ionic liquids show a low toluene/heptane selectivity ( 7 and 4 respectively) and relatively high distribution coefficients (0.85 and 0.37). Also the isoquinolinium ionic liquid shows a low toluene/heptane selectivity: 13. A higher selectivity was expected, due to the double aromatic rings of the isoquinolinium cation. The toluene distribution coefficient with the isoquinolinium containing IL is 0.34 , slightly higher than that with sulfolane (0.33).

The nature of the anion has also an important effect: with $\mathrm{HSO}_{4}^{-}$the toluene distribution coefficient is very low, around 0.07 at $40^{\circ} \mathrm{C}$, for both $\left[\mathrm{Hmim}^{\circ} \mathrm{HSO}_{4}\right.$ and [emim] $\mathrm{HSO}_{4}$. At $75^{\circ} \mathrm{C}$, the distribution coefficients are 0.041 and 0.123 . The distribution coefficients of both toluene and heptane with [emim] containing ionic liquids increase in the following order at $40^{\circ} \mathrm{C}$ : $\mathrm{HSO}_{4}^{-}, \mathrm{C}_{2} \mathrm{H}_{5} \mathrm{SO}_{4}^{-}, \mathrm{BF}_{4}^{-}, \mathrm{CH}_{3} \mathrm{SO}_{3}^{-},\left(\mathrm{C}_{2} \mathrm{H}_{5}\right)_{2} \mathrm{PO}_{4}{ }^{-}$. Since the solubility of heptane increases more in this series than that of toluene, the toluene/heptane selectivity decreases in this order. At $75^{\circ} \mathrm{C}$, the order in the distribution coefficient with the [emim] containing ionic liquids is: $\mathrm{HSO}_{4}^{-}, \mathrm{CH}_{3} \mathrm{SO}_{3}{ }^{-}, \mathrm{C}_{2} \mathrm{H}_{5} \mathrm{SO}_{4}^{-}, \mathrm{BF}_{4}^{-}, \mathrm{C}_{7} \mathrm{H}_{7} \mathrm{SO}_{3},\left(\mathrm{C}_{2} \mathrm{H}_{5}\right)_{2} \mathrm{PO}_{4}{ }^{-}$. The toluene/heptane selectivity at $75^{\circ} \mathrm{C}$ decreases in the following order: $\mathrm{CH}_{3} \mathrm{SO}_{3}^{-}, \mathrm{HSO}_{4}^{-}$, $\mathrm{C}_{2} \mathrm{H}_{5} \mathrm{SO}_{4}^{-}, \mathrm{C}_{7} \mathrm{H}_{7} \mathrm{SO}_{3}, \mathrm{BF}_{4}^{-},\left(\mathrm{C}_{2} \mathrm{H}_{5}\right)_{2} \mathrm{PO}_{4}^{-}$. With tetrafluoroborate as anion, both the toluene distribution coefficients (at $40^{\circ} \mathrm{C}$ : 0.30 for [emim]BF ${ }_{4}, 0.34$ for [bmim]BF $\mathrm{BF}_{4}$ and 0.46 for [mebupy]BF 4 ) and the toluene/heptane selectivities are high (34, 46 and 50 respectively). At $75^{\circ} \mathrm{C}$, also relatively high distribution coefficients $(0.25,0.29$ and 0.45$)$ and selectivities are observed $\left(25,32\right.$ and 39 respectively). The same effect of high selectivities with $\mathrm{BF}_{4}$ containing compounds is reported for olefin/paraffin separations with silver salts. With $\mathrm{AgBF}_{4}$ much higher separation factors are achieved than with other Ag-salts, such as $\mathrm{ClO}_{4}^{-}, \mathrm{CF}_{3} \mathrm{SO}_{3}^{-}, \mathrm{CF}_{3} \mathrm{CO}_{2}^{-}, \mathrm{NO}_{3}^{-}$(Sunderrajan et al., 2001 and Kim et al., 2004). However, 
for [omim] $\mathrm{BF}_{4}$ the toluene distribution coefficient is also high: 0.91 at $40^{\circ} \mathrm{C}$ and 0.69 at $75^{\circ} \mathrm{C}$, but the toluene/heptane selectivity is low: 7.1 and 5.7 . The only [emim] containing ionic liquid with both a higher toluene distribution coefficient and a higher toluene/heptane selectivity than with sulfolane is [emim] tosylate, probably caused by the aromatic character of the anion (toluene sulfonate), since all other ionic liquids with [emim] ${ }^{+}$as cation show lower toluene distribution coefficients than with sulfolane.

From Figure 5 , it is clear that the ionic liquids [bmim]BF ${ }_{4}$, [mebupy]BF 4 and [mebupy] $\mathrm{CH}_{3} \mathrm{SO}_{4}$ exhibit both higher distribution coefficients of toluene and higher toluene/heptane selectivities than sulfolane. Just as with the temperature of $40^{\circ} \mathrm{C}$, the most suitable ionic liquids for the separation of toluene from toluene/heptane mixtures at $75^{\circ} \mathrm{C}$ are the ionic liquids [mebupy] $\mathrm{BF}_{4}$, [mebupy] $\mathrm{CH}_{3} \mathrm{SO}_{4}$ and additionally [emim] tosylate (Figure 6). Since the ionic liquid [mebupy]BF ${ }_{4}$ shows at both temperatures a higher toluene distribution coefficient and a higher toluene/heptane selectivity than sulfolane, this ionic liquid will be used for testing in our extraction pilot plant.

\section{REGENERATION OF THE IONIC LIQUIDS}

Evaporating the organic compounds from the extract could easily regenerate the ionic liquids used in the extraction. Analysis by NMR of both the original ionic liquid and the regenerated product showed no differences between the two samples. This means that no degradation of the ionic liquid after repeated recycling could be detected. This confirms the assumption that the regeneration and recycling of the ionic liquids are indeed simple. The most results shown were obtained with regenerated ionic liquids.

The presence of the ionic liquid [mebupy]BF 4 in the raffinate phase could not be detected. The average concentration of the ionic liquid [emim] ethylsulfate in the raffinate phase, which also contains some toluene, is low: 0.9 mole $\%$ at $40^{\circ} \mathrm{C}$ and $2.5 \mathrm{~mole} \%$ at $75^{\circ} \mathrm{C}$. Removal of these ionic liquids from the raffinate phase is possible by using water, since these ionic liquids are water-soluble.

\section{PROCESS DESIGN}

A preliminary process design has been set up (Figure 7) and a flow-sheeting model is being developed for this extraction to simulate the process. If in the raffinate phase from the extractor, containing aliphatic hydrocarbons, a very small amount of ionic liquid is present, the raffinate is washed with water in order to remove the ionic liquid, which is recycled to the extractor. The extract phase from the extractor, containing the ionic liquid, the extracted aromatic hydrocarbons and the water from the water wash, is heated by low-pressure steam in an evaporator, where the volatile aromatic hydrocarbons and the water are being evaporated. The ionic liquid is recycled to the extractor. The top stream of the evaporator will then undergo a phase separation, where the water is separated from the organic compounds and can be recycled to the water wash. 


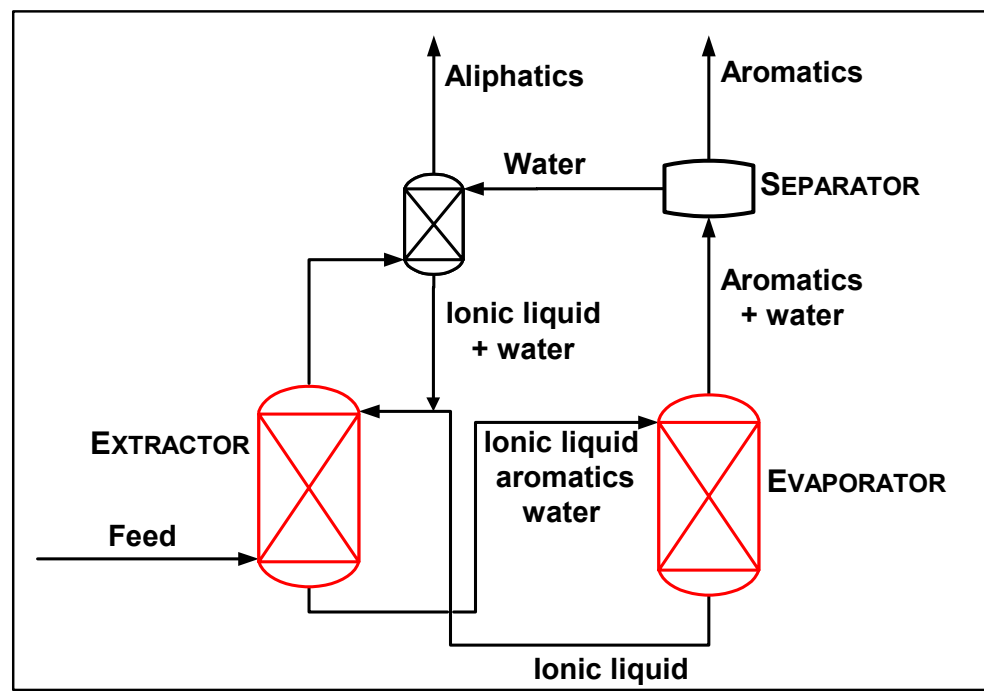

Figure 7. Conceptual process scheme for extraction of aromatic hydrocarbons from aliphatic hydrocarbons with ionic liquids.

From Figure 7, it is apparent that there are only a few process steps for the extraction of aromatics when ionic liquids are used, because regeneration of the ionic liquid is easily done by evaporation or stripping. Preliminary calculations indicate that the investment costs for extraction with ionic liquids are about $50 \%$ lower compared to an extraction with sulfolane, because fewer process steps for the purification of the extract and raffinate phases and for the regeneration of sulfolane are required. Also the energy costs will be lower, because low-pressure steam can be used for the evaporation of the hydrocarbons, while the sulfolane process requires high-pressure steam due to the high temperature, $190^{\circ} \mathrm{C}$, in the solvent stripper.

Optimisation of this process must still be carried out. For instance, the optimum between the solvent to feed ratio vs. the number of stages has to be found: a higher S/F ratio means fewer stages, but higher costs of the solvent. Also, the washing of the raffinate with water needs to be optimised further.

\section{Conclusions}

Of all the ionic liquids tested, [bmim] $\mathrm{BF}_{4}$, [mebupy]BF ${ }_{4}$, [mebupy] $\mathrm{CH}_{3} \mathrm{SO}_{4}$ and at $75^{\circ} \mathrm{C}$ [emim] $\mathrm{C}_{7} \mathrm{H}_{7} \mathrm{SO}_{3}$ are the most suitable ones for extraction of toluene from toluene/heptane mixtures. Both the distribution coefficients of toluene and the toluene/heptane selectivities are higher with these ionic liquids than with sulfolane. The selectivity for the toluene/heptane separation using [mebupy]BF ${ }_{4}$ increases with decreasing toluene content in the feed: from 12 to 53 (95 to $5 \%$ toluene in the feed) at $40^{\circ} \mathrm{C}$ and from 17 to 39 (65 to $10 \%$ toluene in the feed) at $75^{\circ} \mathrm{C}$.

As [mebupy]BF 4 shows the optimal combination of both a high toluene distribution coefficient and a high toluene/heptane selectivity, this ionic liquid will be used for tests in our extraction pilot plant. 
Since ionic liquids have a negligible vapour pressure, evaporating the extracted hydrocarbons from the ionic liquid phase could achieve an easy recovery of the ionic liquid. NMR analysis showed no degradation of the ionic liquids after repeated regeneration and recycling of the ionic liquids.

A conceptual process scheme for the extraction has been set up. Preliminary calculations show that both the investment costs and the energy costs will be considerably lower compared to extraction using sulfolane as the solvent.

\section{REFERENCES}

- Blanchard, L.A.; Brennecke, J.F., Recovery of organic products from ionic liquids using supercritical carbon dioxide, Ind. Eng. Chem. Res. 40 (1) 287-292, (+ 40, 2550), 2001.

- Brennecke J.F.; Maginn, E.J, Ionic Liquids: Innovative Fluids for Chemical Processing, AIChE Journal 47 (11) 2384-2389, 2001.

- David, W.; Letcher, T.M.; Ramjugernath, D.; Raal, J. D., Activity coefficients of hydrocarbon solutes at infinite dilution in the ionic liquid, 1-methyl-3-octylimidazolium chloride from gas-liquid chromatography, J. Chem. Thermodyn. 35 (8) 1335-1341, 2003

- Domańska, U.; Marciniak, A., Solubility of 1-Alkyl-3-methylimidazolium Hexafluorophosphate in Hydrocarbons, J. Chem. Eng. Data 48 (3) 451-456, 2003.

- Dupont, J.; Consorti, C.S.; Spencer, J., Room Temperature Molten Salts: Neoteric "Green" Solvents for Chemical Reactions and Processes, J. Braz. Chem. Soc. 11 (4) 337-344, 2000.

- Gmehling, J.; Krummen, M., Einsatz ionischer Flüssigkeiten als selektieve Lösungsmittel für die Trennung aromatischer Kohlenwasserstoffe von nichtaromatischen Kohlenwasserstoffen durch extraktive Rektifikation und Extraktion, DE 10154052 A1, 10-07-2003.

- Heintz, A.; Kulkokov, D.V.; Verevkin, S.P., Thermodynamic Properties of Mixtures Containing Ionic Liquids. 1. Activity Coefficients at Infinite Dilution of Alkanes, Alkenes, and Alkylbenzenes in 4-Methyl- $n$-butylpyridinium Tetrafluoroborate Using Gas-Liquid Chromatography, J. Chem. Eng. Data, 46, 1526-1529, 2001.

- Heintz, A.; Kulikov, D.V.; Verevkin, S.P., Thermodynamic Properties of Mixtures Containing Ionic Liquids. 2. Activity Coefficients at Infinite Dilution of Hydrocarbons and Polar Solutes in 1-Methyl-3-ethyl-imidazolium Bis(trifluoromethyl-sulfonyl) Amide and in 1,2-Dimethyl-3-ethyl-imidazolium Bis(trifluoromethyl-sulfonyl) Amide Using Gas-Liquid Chromatography, J. Chem. Eng. Data 47, 894-899, 2002.

- Holbrey, J.D.; Reichert, W.M.; Nieuwenhuyzen, M.; Sheppard, O.; Hardacre, C.; Rogers, R.D., Liquid clathrate formation in ionic liquid-aromatic mixtures, Chem. Commun. 4, 476-477, 2003.

- Holbrey, J.D.; Reichert, W.M.; Swatloski, R.P.; Broker, G.A.; Pitner, W.R.; Seddon, K.R.; Rogers, R.D., Efficient, halide free synthesis of new, low cost ionic liquids: 1,3-dialkylimidazolium salts containing methyl- and ethylsulfate anions, Green Chem. 4, 407-413, 2002. 
- Huddleston, J.G.; Willauer, H.D.; Swatloski, R.P.; Visser, A.E.; Rogers, R.D., Room temperature ionic liquids as novel media for 'clean' liquid-liquid extraction, Chem. Commun. 16, 1765-1766, 1998.

- Kim, J.H.; Won, J.; Kang, Y.S., Silver polymer electrolytes by $\pi$-complexation of silver ions with polymer containing $\mathrm{C}=\mathrm{C}$ bond and their application to facilitated olefin transport membranes, J. Membr. Sci. 237, 199-202, 2004.

- Krummen, M.; Wasserscheid, P.; Gmehling J., Measurement of Activity Coefficients at Infinite Dilution in Ionic Liquids using the Dilutor Technique, J.Chem.

Eng. Data 47, 1411-1417, 2002.Selvan, M.S.; McKinley, M.D.; Dubois, R.H.; Atwood, J.L., Liquid-Liquid Equilibria for Toluene + Heptane + 1-Ethyl-3methylimidazolium Triiodide and Toluene + Heptane + 1-Butyl-3-methylimidazolium Triiodide, J. Chem. Eng. Data 45, 841-845, 2000.

- Letcher, T.M.; Deenadayalu, N., Ternary liquid-liquid equilibria for mixtures of 1methyl-3-octyl-imidazolium chloride+benzene+an alkane at $\mathrm{T}=298.2 \mathrm{~K}$ and $1 \mathrm{~atm}, \mathrm{~J}$. Chem. Thermodyn. 35, 67-76, 2003.

- Letcher, T.M.; Soko, B.; Ramjugernath, D.; Deenadayalu, N.; Nevines, A.; Naicker, P.K., Activity Coefficients at Infinite Dilution of Organic Solutes in 1-Hexyl-3methylimidazolium Hexafluorophosphate from Gas-Liquid Chromatography, J. Chem. Eng. Data 48 708-711, 2003.

- Meindersma, G.W.; Podt, J.G.; Gutiérrez Meseguer, M.; Haan, A.B. de, Ionic liquids as alternatives to organic solvents in liquid-liquid extraction of aromatics, in: Ionic Liquids III: Progress and Prospects (R.D. Rogers and K.R. Seddon, editors), ACS Symposium Series, 2004, submitted

- Swatloski, R.P.; Holbrey, J.D.; Rogers, R.D., lonic liquids are not always green: hydrolysis of 1-butyl-3-methylimidazolium hexafluoroborate, Green Chem. 5 (4), 361-363, 2003.

- Sunderrajan, S.; Freeman, B.D.; Hall, C.K.; Pinnau, I., Propane and propylene sorption in solid polymer electrolytes based on poly(ethylene oxide) and silver salts, J. Membr. Sci. 182, 1-12, 2001.

- Weissermel, K.; Arpe, H.-J., Industrial Organic Chemistry, $4^{\text {th }}$ Completely Revised Edition, Wiley-VCH, Weinheim, D., pp 313-336, 2003.

- Willems, J. and Nys, J., The preparation of some quaternary ammonium salts, Bull. Soc. Chim. Belg. 66, 502-511, 1957. 